\title{
Renal Sympathetic Denervation Using a Novel Device: A Clinical Case Discussion and Literature Update
}

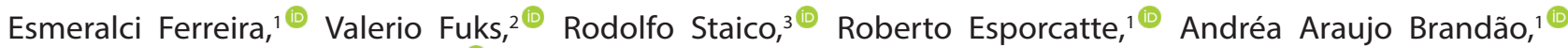 \\ Denilson Campos Albuquerque ${ }^{1}$
}

Universidade do Estado do Rio de Janeiro, ${ }^{\prime}$ Rio de Janeiro, RJ - Brazil Hospital Federal dos Servidores do Estado, ${ }^{2}$ Rio de Janeiro, RJ - Brazil Instituto Dante Pazzanese de Cardiologia, ${ }^{3}$ São Paulo, SP-Brazil

\section{Introduction}

Resistant hypertension ( $\mathrm{RH})$ is directly related to increased mortality, severe renal changes, and cardiac and cerebrovascular diseases, due to lack of adequate drug treatment. ${ }^{1}$ Cardiovascular disease mortality increases progressively and linearly as $\mathrm{BP}$ increases, whereas $\mathrm{BP}$ lowering is associated with significantly reduced risks. ${ }^{2-5}$ Increased sympathetic tone in renal arteries is one of the major components of $\mathrm{RH}$, and catheters have been developed using several technologies which allow for radiofrequency ablation (RA) and blood pressure (BP) reduction. The discussions and controversies about the effectiveness of this treatment are quite broad, especially when associated with the use of new devices. In this clinical case study, with an 18-month follow-up, we describe the development of knowledge regarding this technique and its evidence basis.

\section{Clinical Case}

Male patient, 48 years old, with uncontrolled $\mathrm{RH}$, under treatment with seven antihypertensive drugs at maximum tolerated daily doses (Atenolol $100 \mathrm{mg}$, Furosemide $80 \mathrm{mg}$, Hydrochlorothiazide $25 \mathrm{mg}$, Spironolactone 25 mg, Hydralazine Hydrochloride 200 mg, Methyldopa $1000 \mathrm{mg}$ and Telmisartan $160 \mathrm{mg}$ ). Office blood pressure remained above $185 / 105 \mathrm{mmHg}$

\section{Keywords}

Hypertension; Antihypertensive Agents, Renal Artery; Aortic Coarctation; Cushing Syndrome; Comorbidity; Sympathectomy; Vascular Access Devices/trends. and mean arterial pressures measured by Ambulatory Blood Pressure Monitoring (ABPM) were $186 / 120 \mathrm{mmHg}$ over the total period, $193 / 127 \mathrm{mmHg}$ while awake, and 174/107 mmHg during sleep. All major causes of secondary hypertension (primary hyperaldosteronism, pheochromocytoma, aortic coarctation, Cushing syndrome, hyperthyroidism, renal parenchymal disease, renal artery stenosis, obstructive sleep apnea syndrome) were excluded by biochemical, graphic and imaging exams. In late November 2017, the patient was admitted due to failure to obtain adequate BP control. In that occasion, complementary exams, such as electrocardiogram, echocardiogram and renal function, did not reveal abnormal findings.

Renal Sympathetic Denervation (RSD) was indicated due to the ineffectiveness of medical treatment and the change of habits to which he was submitted. The procedure was performed on November 17, 2018.

The Symplicity Spyral ${ }^{\circledR}$ catheter (Medtronic, Galway, Ireland) (Figure 1) was used, which allows for multiple simultaneous radiofrequency (RF) ablations in the renal artery.

We opted for conscious sedation with benzodiazepine and venous opioid, to avoid intense visceral pain, caused by RF ablation, and possible patient mobilization. The angiographic image showed anatomy favorable for RSD, with adequate-caliber major arteries and bilateral branches, and absence of accessory branches (Figure 2).

Access to the renal arteries was facilitated by an angioplasty guidewire, which allowed for the placement of the Symplicity Spyral catheter, whose helical pattern conforms to the lumen, taking the shape of these branches, and delivering RF energy simultaneously to

Mailing Address: Esmeralci Ferreira

Avenida 28 de Setembro,s/n. Postal Code: 20550-900, Rio de Janeiro, RJ - Brazil.

E-mail: esmeralci@gmail.com 


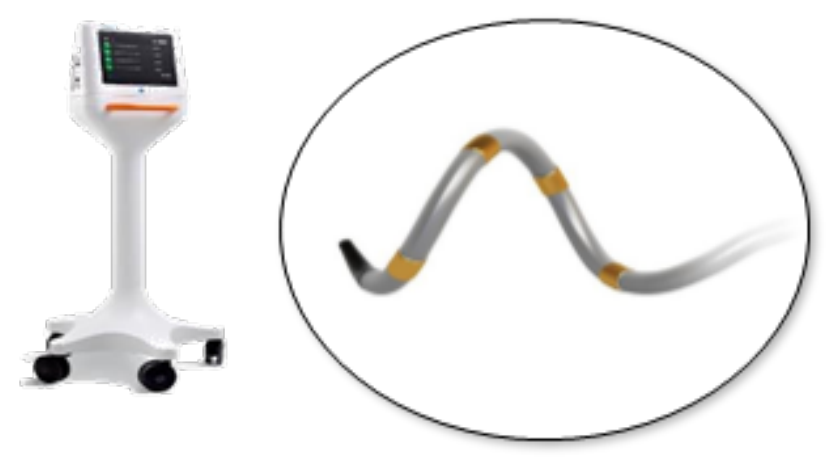

Figure 1 - The Symplicity G3 generator (Medtronic)

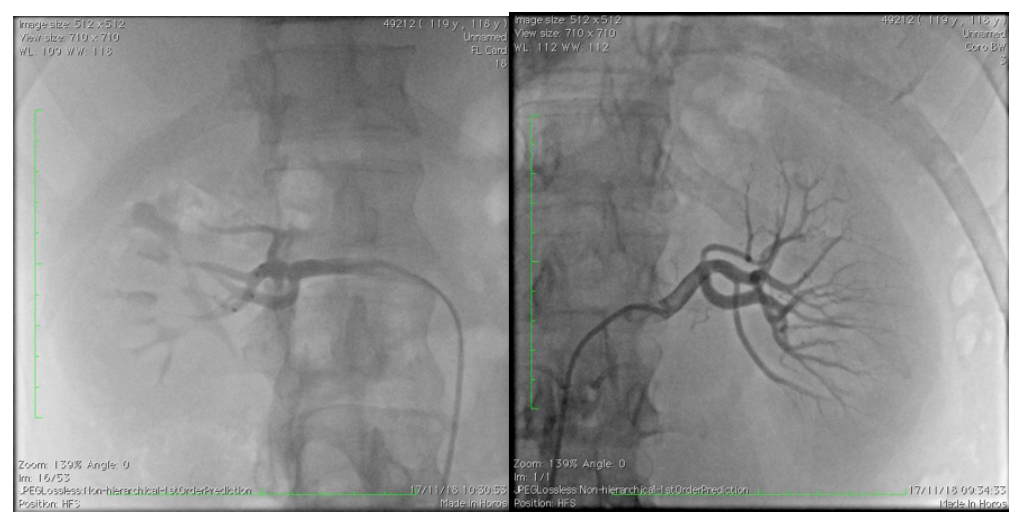

Figure 2 - Selective arteriography of renal arteries.

all 4 quadrants for 60 seconds. After that, ablations were performed in the main renal arteries of both kidneys (Figure 3). We performed 27 RF ablations in all segments of the renal arteries, with effective treatment of 59 sites, with 11 ablations being applied to the left renal artery, with 25 sites effectively treated, and 16 ablations to the right renal artery, with 34 sites effectively treated. Control arteriography did not reveal angiographic complications. There were no hemorrhagic complications at the puncture site. The contrast volume of the procedure was $200 \mathrm{ml}$ and the procedure time was 88 minutes.

During hospitalization, the patient remained asymptomatic and was discharged after 24 hours, with no complications and BP at stable normal levels. For 18 months, he evolved well, with a decrease in office and ABPM BP. The mean ABPM values over the total period were $125 / 79 \mathrm{mmHg}$ in the 2-month follow-up, 149/97 $\mathrm{mmHg}$ in the 8-month follow-up, and 147/196 $\mathrm{mmHg}$ in the 18-month follow-up (Figure 4). The laboratory tests, the antihypertensive therapy and the labor activity profile, without physical activities, remained unchanged.

\section{Discussion}

Systemic Arterial Hypertension (SAH) is the most prevalent disease worldwide, affecting between 30 to $40 \%$ of the population in developing countries, with serious consequences in the long term. ${ }^{1,2}$ Even a small reduction in BP levels results in significant gains regarding cerebrovascular complications. ${ }^{3}$ Uncontrolled $\mathrm{RH}$ is defined as $\mathrm{BP} \geq 140 / 90 \mathrm{mmHg}$ in individuals under treatment with at least three antihypertensive medications at maximum tolerated daily doses, when secondary causes are excluded. ${ }^{4}$ It is estimated that $2-16 \%$ of people with hypertension are resistant. According to data from the Ministry of Health, the prevalence of hypertension in 

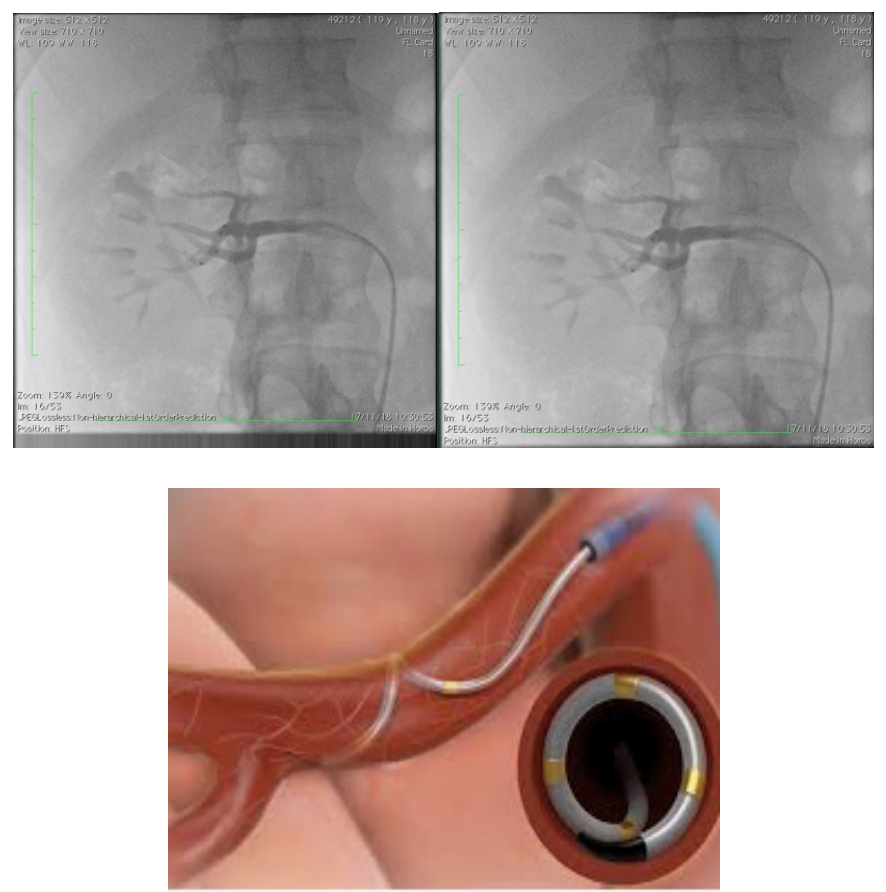

Figure 3 - Symplicity Spyral (Medtronic) Catheter with a helical configuration in the renal artery.

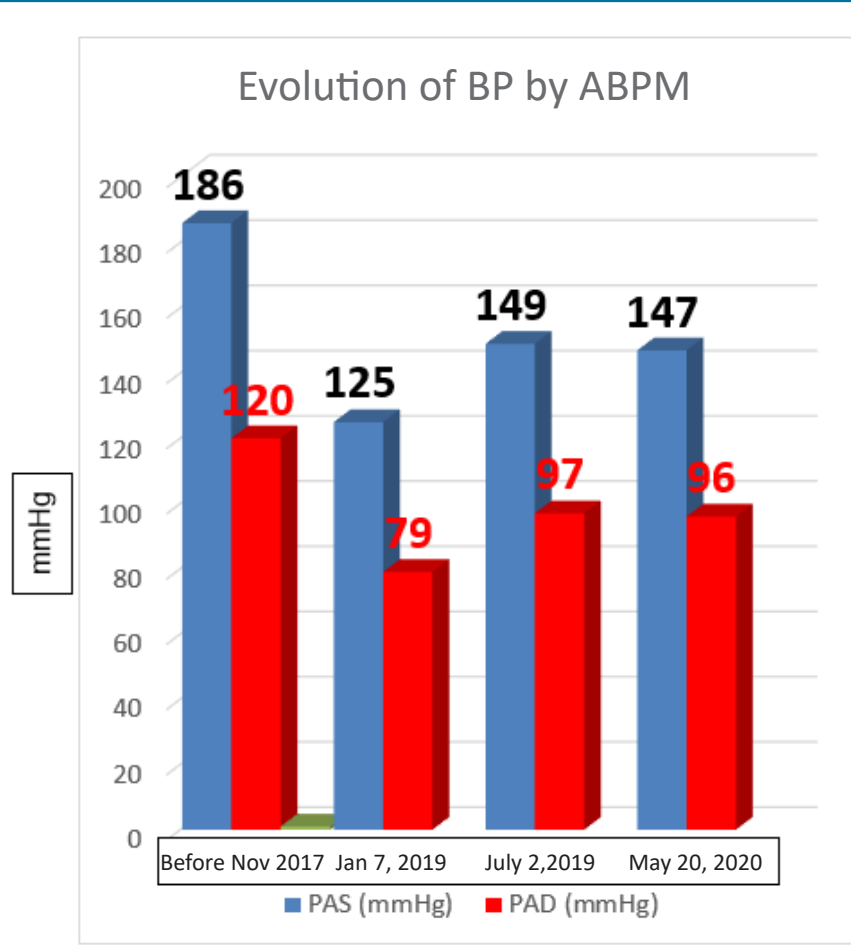

Figure 4 - Evolution of BP by ABPM 1 year before RSD, and within 2, 8 e 18 months after the procedure. BP (Blood Pressure); ABMP (Ambulatory Blood Pressure Monitoring); RSD (Renal Sympathetic Denervation); SBP (Systolic Blood Pressure); DPB (Diastolic Blood Pressure) 
the Brazilian population is $24.7 \%$. With an estimated adult population of 86 million inhabitants, Brazil has at least 400,000 patients with $\mathrm{RH} .^{5}$

In general, resistance is multifactorial, and it is the main cause of medication non-adherence. ${ }^{6}$ Factors associated with health habits, such as sedentary lifestyles, increased sodium and alcohol intake, as well as the use of medication like non-steroidal antiinflammatory drugs, also contribute to treatment resistance. Even after correction of all these factors, BP levels remain elevated in a subgroup of patients. The sympathetic nervous system has a major role in this condition, and increased sympathetic tone is one of the main components of RH. The efferent innervation of the central nervous system arises from the second sympathetic ganglion and reaches the kidney through a network of fibers that spread across the renal artery adventitia. These fibers stimulate the the Renin-Angiotensin-Aldosterone System (RAAS), eventually resulting in sodium and water retention. The final product of this system, angiotensin II, is a potent vasoconstrictor that decreases renal blood flow and contributes to increased systemic blood pressure. Afferent innervation carries feedback from the kidney to the hypothalamus, completing and perpetuating the cycle. ${ }^{7,8}$ In the 1950's, surgical sympathectomy, with the removal of abdominal and lumbar nerve plexuses, presented significant results in decreasing blood pressure, but with high morbidity and mortality rates. ${ }^{9}$ Recently, the extension of renal artery sympathetic innervation has been demonstrated, with a predominance of sympathetic nerve fibers closer to the lumen in the distal part of the arteries. ${ }^{10}$

\section{Initial Studies}

Studies on the safety of the ablation of sympathetic innervation using intra-arterial devices with several types of action mechanisms, i.e., RF RSD, began in 2009, and it was the most widely used technology. The Symplicity HTN $1^{11}$ trial was the first human study to confirm the safety of the method, followed by the randomized Symplicity HTN 2 trial. ${ }^{12}$ Both studies showed a significant and sustained reduction in SBP (about $25 \mathrm{mmHg}$ ) and few complications, which led to expectations about the long-term benefits of the method for reducing cardiovascular complications. ${ }^{1,2}$ The Symplicity HTN-3 trial, conducted in the United States, randomly assigned 535 patients with $\mathrm{RH}$ (ratio
2:1), comparing RSD with the control procedure group (CPG). The latter consisted of patients submitted to renal arteriography only, with no therapeutic intervention, in order to eliminate the placebo effect. The result of the primary endpoint (a decrease of 5 $\mathrm{mmHg}$ in systolic BP within six months) was negative, although there was a significant reduction in systolic BP in both groups. ${ }^{13}$ Basically, four factors account for the lack of success of the SYMPLICITY HTN-3 trial, and the main one refers to the inadequate technique used, in which only $6 \%$ of the patients received a four-quadrant ablation in both arteries. The study was perfomed using the Symplicity Flex ${ }^{\circledR}$ catheter (Medtronic, Galway, Ireland), with a monopolar distal electrode. The device was difficult to manipulate, and required the use of more radiation and contrast to perform RF ablations in several points. For this reason, most investigators performed only one or two procedures. Other factors associated with failure were: medication changes (up to $40 \%$ ) in the post-procedure period in both groups, the inclusion of patients with isolated systolic SAH, and the African American group, in which the drop in BP was more evident in the sham group compared to the RSD group. ${ }^{14}$ Simultaneously, the Global SYMPLICITY Registry (GSR), a multicenter registry which assessed 1,199 patients during 3 years, showed an important reduction in SBP (ABPM - 8.0 $\mathrm{mmHg}$ and Office $-16.5 \mathrm{mmHg}$ ), without impairing renal function. ${ }^{15}$ The French randomized study DENERHTN, which compared RSD with optimized antihypertensive therapy, presented expressive results, with a reduction in SBP of $-5.9 \mathrm{~mm} \mathrm{Hg}(-11.3$ to $-0.5 ; \mathrm{p}=0.0329) .{ }^{16}$ These studies did not compare RSD with the CPG, which limits the validation of their findings. The identification and correction of the fators that resulted in the failure of SYMPLICITY HTN-3, combined with the sucess of RSD in other studies, and the development of a novel quadripolar Symplicity Spyral catheter (Medtronic, Galway, Ireland), which allows for simultaneous circumferential ablation with access the branches fostered this evolution of Symplicity Spiral. This easier-to-use device allows for more ablation, because it reaches the four quadrants of the artery, simultaneously and safely. RF energy delivery is also predictable, with a shorter ablation time compared to the previous device. At first, a limitating factor would be less penetration of RF (an average of $4 \mathrm{~mm}$ ). However, since the nerves are located closer to the lumen in the arteries, most of them are accessed by 
the device. Another limitation of this device is related with the anatomy of the arteries. The distal segment of the catheter, where the electrodes are located, adapts to lumen diameters ranging from 3 to $8 \mathrm{~mm}$. Accessory arteries and branches with smaller lumen diameter cannot be acessed and, therefore, represent a possible cause of treatment failure, since they are also innervated.

\section{Post Symplicity HTN-3 Studies}

Based on these observations, other studies were conducted. The Spyral-HTN OFF-MED trial, performed with this new device, was conceived as proof of concept to assess the biological viability of RSD. A total of 80 patients with mild-to-moderate SAH (BP <180 $\mathrm{mmHg}$ ), in the absence of antihypertensive medication evaluated by laboratory testing, were randomly assigned (1:1) to either RSD or CPG. The results within 3 months showed a positive effect of RSD, with a decrease in ABMP SBP and diastolic blood pressure (DBP) of $-5.0(\mathrm{p}=0.0414)$ and $-4.4(\mathrm{p}=0.0024) \mathrm{mmHg}$, and a reduction in office BP of $-7.7(\mathrm{p}=0.0155)$ and -4.9 $(p=0.0077) \mathrm{mmHg}$, respectively, corresponding to the difference of what was obtained in the CPG. ${ }^{17}$ Later, the Spyral ON-MED trial, using the same device, included patients with the same epidemiological characteristics, but who were taking up to three antihypertensive agents. The result within six months was positive for RSD versus CPG, with a sustained drop in 24-hour ABPM SBP and DBP of $-7.0 \mathrm{mmHg}(\mathrm{p}=0.0059)$ and $-4.3 \mathrm{mmHg}(\mathrm{p}=0.0174)$, and a reduction in office SBP and DBP of $-6.6 \mathrm{~mm} \mathrm{Hg}(\mathrm{p}=0.0250)$ and $-4.2 \mathrm{~mm} \mathrm{Hg}$ $(p=0.0190){ }^{18}$

Simultaneously with these studies, the RADIANCEHTN SOLO Trial of Ultrasound Renal Denervation (Paradise ${ }^{\circledR}$ system) (ReCor Medical, Palo Alto, CA, USA) was performed. A total of 176 patients with mildto-moderate SAH off antihypertensive medication were randomly assigned (1:1) to RSD versus CPG. Daytime ABPM SBP ranged from $-8.5 \mathrm{~mm} \mathrm{Hg}$ to $-2.2 \mathrm{~mm} \mathrm{Hg}$ within 2 months (the adjusted difference between the groups was $-6.3 \mathrm{~mm} \mathrm{Hg} \mathrm{p=0.0001).}{ }^{19}$ After this phase, optimized antihypertensive treatment was initiated in patients with BP greater than 135/80 mmHg. After six months, the initial result was maintained, with reduced $B P$ values and less antihypertensive medication in the RSD group. During six months, $65.2 \%$ of patients in the RSD group were treated with the optimized antihypertensive therapy versus $84.5 \%$ in the CPG $(p=0.008)$ and mean antihypertensive drug use was lower in the RSD group compared to the CG $(0.9 \pm 0.9$ $x 1.3 \pm 0.9(p=0.010))$. Even with a smaller amount of medication, RSD was associated with larger reductions in ABMP SBP when compared with the CG group $(-18.1 \pm 12.2 \times-15.6 \pm 13.2 \mathrm{mmHg}$, respectively). The adjusted difference in $\mathrm{BP}$ and the number of drugs was $-4.3 \mathrm{mmHg}$, CI-95\%, -7.9 to $-0.6(\mathrm{p}=0.024){ }^{20}$

The RADIOSOUND-HTN trial compared both technologies by randomly assigning 120 patients in a 1:1:1 manner to 3 groups: 1) RSD of the main renal artery only, using the Symplicity Spyral catheter; 2) RSD of the main renal artery and accessory branches using the Symplicity Spyral catheter, and 3) RSD of the the main renal artery using the Paradise catheter. The group that received the ultrasound catheter-based therapy showed greater BP reduction compared with the two groups that received RF catheter therapy $(-13.2$ $x 6.5 \mathrm{mmHg}$ within 3 months, $\mathrm{P}=0.042$ ). No difference was observed regarding $\mathrm{BP}$ reductions between the groups treated with RF. Multicenter studies with more participants, follow-up and time are needed to establish a more definitive comparison between these technologies. $^{21}$

In a meta-analysis comparing the results of six first- and second generation randomized trials for RSD versus GPC, with 977 participants, Sardar et al., ${ }^{22}$ observed ignificant SBP and DBP reductions, in both ABPM and Office BP, in RSD versus GPC, as well as low complication rates. The results were more expressive in the second-generation trials, in which the confounding factors previously described had been excluded. ${ }^{14,22}$

The proof-of-concept trials validated RSD from the biological point of view, and were not designed to obtain statistical power for positivity responses as their primary efficacy endpoint.

The SPYRAL HTN-OFF MED Pivotal multicentre, randomized trial assigned 331 moderate hypertensive patients off antihypertensive medication to either RSD $(n=166)$ and CPG $(n=165)$. With a Bayesian design, this trial used evidence from the SPYRAL HTN-OFF MED pilot trial. The primary efficacy endpoint was baselineadjusted change in 24-h systolic blood pressure and the secondary efficacy endpoint was baseline-adjusted change in office systolic blood pressure from baseline within 3 months. The primary and secondary efficacy endpoints were met, with posterior probability of 
superiority more than $99 \%$ for both. The treatment difference between the two groups for $24-\mathrm{h}$ systolic blood pressure was $-3.9 \mathrm{~mm} \mathrm{Hg}$ (Bayesian 95\% credible interval -6.2 to -1.6$)$ and for office systolic blood pressure the difference was $-6.5 \mathrm{~mm} \mathrm{Hg}(-9.6$ to -3.5$)$. The study showed the superiority of RSD compared with a sham procedure, which ultimately corresponds to the clinical treatment group. ${ }^{23}$

In a meta-analysis of 5,769 subjects submitted to RSD, Townsend et al., ${ }^{24}$ describe renal artery dissection requiring stenting in 24 patients $(0.41 \%)$. Most events (79\%) occurred in the in-hospital phase or within the first year of follow-up. Thus, the need for post-treatment intervention is not common and the procedure is considered very safe. ${ }^{24}$

The Brazilian Position Statement on Resistant Hypertension - 2020 describes that: "based on this evidence, RSD is currently an alternative only for patients with UC-RHTN with optimized pharmacological treatment and proven therapeutic adherence or with important drug-related adverse effects, to be always performed at referral centers trained for the procedure". ${ }^{25}$

We managed to demonstrate that, using the same techniques prescribed in the studies, similar positive results were obtained. This young patient with $\mathrm{RH}$, treated with RSD, presented excellent results within eighteen months. After a significant initial drop in BP (- 61 / - $41 \mathrm{mmHg}$ ) within 2 months, there was BP stabilization at higher levels, but still with a very significant reduction $(-39 /-24 \mathrm{mmHg}$ ) in relation to baseline after 18 months, and clear benefits regarding cardiovascular complications. ${ }^{3}$ The significant reduction in BP may be related with the placebo effect or with the increased baseline BP prior to procedure. ${ }^{26}$

The changes in patient seletion and technique, and the results of recent randomized trials bring new perspectives into the treatment of $\mathrm{RH}$, whose pressure control is inadequate, despite all the available drug armamentarium. The most robust randomized trials have already shown the biological validity and clinical utility of RSD. Real-world registries indicate that the ideal patients for receiving this technique are those at high cardiovascular risk, mainly young, and with very high SBP and DBP levels. ${ }^{15}$
In addition, it is important to highlight some encouraging studies that have applied RSD in patients with heart failure with reduced ejection fraction ${ }^{27}$, Chagas Disease ${ }^{28}$, atrial ${ }^{29}$ and ventricular malignant arrhythmias $^{30}$, sleep apnea ${ }^{31}$ and changes in glucose metabolism $^{32}$, i.e., pathologies that include increased sympathetic tonus in their genesis. ${ }^{33}$

\section{Conclusion}

We present the case of a young, uncontrolled hypertension resistant patient submitted to sympathetic renal denervation using the Symplicity Spyral RF system with sustained results in 24-hour ABPM BP within 18 months. We approached $\mathrm{RH}$ and the several available interventionist treatment techniques. We opted for the use of the the aforementioned device especially due to the excellent results presented in clinical trials, in addition to the low complication rates registered in all the studies presented.

\section{Author contributions}

Conception and design of the research: Ferreira E, Fuks V, Esporcatte R. Acquisition of data: Ferreira E. Writing of the manuscript: Ferreira E, Fuks V, Staico R, Brandão AA. Critical revision of the manuscript for intellectual content: Ferreira E, Esporcatte R, Brandão AA, Albuquerque DC.

\section{Potential Conflict of Interest}

No potential conflict of interest relevant to this article was reported.

\section{Sources of Funding}

There were no external funding sources for this study.

\section{Study Association}

This study is not associated with any thesis or dissertation work.

\section{Ethics approval and consent to participate}

This article does not contain any studies with human participants or animals performed by any of the authors. 


\section{References}

1. Lloyd-Jones D, Adams R, Carnethon M,De Simone G, Ferguson TB, Flegal $\mathrm{K}$, et al. Heart disease and stroke statistics - 2009 update: a report from the American heart association statistics committee and stroke statistics subcommittee. Circulation. 2009;119(3):e21-181.

2. Kearney PM, Whelton M, Reynolds K, Muntner P, Whelton PK, He J. Global burden of hypertension: analysis of worldwide data. Lancet. 2005;365(9455): 217-23

3. Ettehad D, Emdin CA, Kiran A, Anderson SG, Callender T, Emberson $\mathrm{J}$, et al. Blood pressure lowering for prevention of cardiovascular disease and death: a systematic review and meta-analysis. Lancet. 2016;387(10022):957-67.

4. Sheppard JP, Martin U, McManus RJ. Diagnosis and Management of Resistant Hypertension. Heart. 2017;103(16):1295-302.

5. Vrijens B, Vincze G, Kristanto P, Urquhart J, Burnier M. Adherence to prescribed antihypertensive drug treatments: longitudinal study of electronically compiled dosing histories. BMJ. 2008 May 17; 336(7653):1114-7.

6. Instituto de Geografia e Estatística. (IBGE). [Citado em 24 junho 2019]. Disponível em: https://www.ibge.gov.br/.

7. Tuck ML.The sympathetic nervous system in essential hypertension. Am Heart J. 1986 Oct;-1-12(4):877-86.

8. Schlaich MP, Lambert E, Kaye DM, Krozowski Z, Campbell DJ, Lambert G, et al. Sympathetic augmentation in hypertension: role of nerve firing, norepinephrine reuptake, and angiotensin neuromodulation. Hypertension. 2004;43(2):169-75.

9. Smithwick RH, Thompson JE. Splanchnicectomy for essential hypertension; results in 1,266 cases. J Am Med Assoc. 1953;152(16):1501-4.

10. Sakakura K, Ladich E, Cheng Q, Otruka F, Yahagi K, Fowler DR, et al. Anatomic assessment of sympathetic peri-arterial renal nerves in man. J Am Coll Cardiol. 2014; 64(7):635-43.

11. Symplicity HTN-1 Investigators. Catheter-based renal sympathetic denervation for resistant hypertension: durability of blood pressure reduction out to 24 months. Hypertension. 2011;57(5):911-7.

12. Esler MD, Krum H, Sobótica PA, Schlaich MP, Schmieder RE, Bohm M, et al. Renal sympathetic denervation in patients with treatment-resistant hypertension (the Symplicity HTN-2 trial): a randomised controlled trial. Lancet. 2010;376(9756):1903-9.

13. Bhatt DL, Kandzari DE, O'Neill WW, D'Agostino R, Flack JM, Katzen BT, et al. SYMPLICITY HTN-3 Investigators. A controlled trial of renal denervation for resistant hypertension. N Engl J Med. 2014;370(15):1393-401.

14. Epstein M, de Marchena. Is the failure of SYMPLICITY HTN-3 trial to meet its efficacy endpoint the "end of the road" for renal denervation? J Am Soc Hypertens. 2015 Feb;9(2):140-9.

15. Mahfoud F, Böhm M, Schmieder R, Narkiewicz K, Ewen S, Ruilope, et al Effects of renal denervation on kidney function and long-term outcomes: 3-year follow-up from the Global SYMPLICITY Registry. Eur Heart J. 2019;40(42):3474-82.

16. Azizi M, SapovalM, GosseP, Monge M, Bobrie G, Delsart P, et al. Optimum and stepped care standardised antihypertensive treatment with or without renal denervation for resistant hypertension (DENERHTN): a multicentre, open-label, randomised controlled trial. Lancet. 2015;385(9981):1957-65.

17. Townsend RR, Mahfoud F, Kandzari DE, Kario K, Pocock S, Weber MA, et al. Catheter-based renal denervation in patients with uncontrolled hypertension in the absence of antihypertensive medications (Spyral HTN OFF- MED): a randomised, sham-controlled, proof-of-concept trial. Lancet . 2017;390(10108): 2160-70.

18. Kandzari DE, Böhm M, Mahfoud F, Townsend RR, Weber MA, Pocock S, et al. SPYRAL HTN-ON MED Trial Investigators. Effect of renal denervation on blood pres- sure in the presence of antihypertensive drugs: 6-month efficacy and safety results from the SPYRAL HTN-ON MED proof-of-con- cept randomised trial. Lancet. 2018;391(10137):2346-55.
19. Azizi M, Schmieder RE, Mahfoud F, Weber MA, Daemen J, Davies $\mathrm{J}$, et al RADIANCE-HTN Investigators. Endovascular ultrasound renal denervation to treat hypertension (RADIANCE-HTN SOLO): a multicentre, international, single- blind, randomised, sham-controlled trial. Lancet. 2018;391(10137):2335-45.

20. Azizi M, Schmieder RE, Mahfoud F, Weber MA, Daemen J, Lobo MD, et al. RADIANCE-HTN Investigators. Six-Month Results of TreatmentBlinded Medication Titration for Hypertension Control Following Randomization to Endovascular Ultrasound Renal Denervation or a Sham Procedure in the RADIANCE-HTN SOLO Trial. Circulation. 2019 Mar 17.

21. Fengler K, Rommel K-P, Blazek S, Besler C, Hartung P, von Roeder $\mathrm{M}$, et al. A three-arm randomized trial of Different Renal Denervation Devices and Techniques in Patients with Resistant Hypertension (RADIOSOUND-HTN). Circulation. 2019;139(5):590-600

22. Sardar P, Bhatt DL, Kirtane AJ, Kennedy KF, Chatterjee S, Giri J, et al. Sham-Controlled Randomized Trials of Catheter-Based Renal Denervation in Patients With Hypertension. J Am Coll Cardiol. 2019 Apr 9;73(13):1633-42.

23. Böhm M, Kario K, Kandzari DE, Mahfoud F, Weber MA, Schmieder $\mathrm{RE}$, et al. Efficacy of catheter-based renal denervation in the absence of antihypertensive medications (SPYRAL HTN-OFF MED Pivotal): a multicentre, randomised, sham-controlled trial Lancet. 2020;395(10234): 1444-51

24. Townsend RR, Walton A, Hettrick DA, Hickey GL, Weill J, Sharp ASP, et al. Review and meta-analysis of renal artery damage following percutaneous renal denervation with radiofrequency renal artery ablation. EuroIntervention. 2020;16(1):89-96

25. Yugar-Toledo JC, Moreno Júnior H, Gus M, Rosito GBA, Scala LCN Muxfeldt ES, et al. Posicionamento Brasileiro sobre Hipertensão Arterial Resistente - 2020. Arq Bras Cardiol. 2020;114(3):576-96

26. Reshetnik A, Gohlisch C, Scheurig-Münkler C, De Bucourt M, Zidek W, Tolle $\mathrm{M}$, et al. Predictors for success in renal denervation-a single centre retrospective analysis [published correction appears in Sci Rep. 2019 Aug 22;9(1):12380].

27. Chen W, Ling Z, Xu Y, Liu Z, Su L, Du H, et al. Preliminary effects of renal denervation with saline irrigated catheter on cardiac systolic function in patients with heart failure: a prospective, randomized, controlled. Pilot Study Catheter Cardiovasc Interv. 2017;89(4):E153-e61.

28. Spadaro AG, Bocchi EA, Souza GE, Esteves Filho A, Mariani Jr J, Campos $\mathrm{CM}$, et al. Renal denervation in patients with heart failure secondary to Chagas' disease: A pilot randomized controlled trial. Catheter Cardiovasc Interv. 2019;94(4):644-50.

29. Steinberg JS, Shabanov V, Ponomarev D,Losik D, Ivanickiy E, Kropotkin E, et al. Effect of Renal Denervation and Catheter Ablation vs Catheter Ablation Alone on Atrial Fibrillation Recurrence Among Patients With Paroxysmal Atrial Fibrillation and Hypertension: The ERADICATE-AF Randomized Clinical Trial [published correction appears in JAMA. 2020 Mar 3;323(9):896]. JAMA. 2020;323(3):248-55

30. Armaganijan LV, Staico R, Moreira DA, Lopes RD, Medeiros PTJ, Habib $\mathrm{R}$, et al. 6-Month Outcomes in Patients With Implantable CardioverterDefibrillators Undergoing Renal Sympathetic Denervation for the Treatment of Refractory Ventricular Arrhythmias. JACC Cardiovasc Interv. 2015;8(7):984-90.

31. Warchol-Celinska E, Prejbisz A, Kadziela J, Florczak E, Januszewicz M, Michalowska I, et al. Renal denervation in resistant hypertension and obstructive sleep apnea. Randomized Proof-of-Concept Phase II Trial. Hypertension.2018;72:381-90.

32. Mahfoud F, Schlaich M, Kindermann I, Ukena C, Cremers B, BrandtMC, et al. Effect of renal sympathetic denervation on glucose metabolism in patients with resistant hypertension: a pilot study. Circulation. 2011;123(18):1940-6

33. Brandão A; Campana EMG; Magalhães MEC; Ferreira E. Renal sympathetic denervation for resistant hypertension treatment: Current perspectives. Arq. Bras. Cardiol. [online]. 2013, vol.101, n.4, pp.364371. Epub Sep 13, 2013. ISSN 0066-782X. 